DOI: $10.1515 / \mathrm{rpp}-2015-0031$

Postgraduate Student, LUDMYLA KOSTINA

Institute of Pedagogical and Adult Education, Ukraine Address: 9 Berlynskoho St., Kyiv, 04060, Ukraine E-mail: kostinaluda@rambler.ru

\title{
TEACHER PROFESSINAL DEVELOPMENT STRATEGIES IN AUSTRALIAN GOVERNMENT AND PROFESSIONAL ASSOCIATIONS DOCUMENTS
}

\begin{abstract}
Teacher in Australia is determined as an active participant of professional community with high level of collaboration, professional development coherent activities and collaborative learning practice. Thus, teacher quality is one of critical factors affecting student outcomes. The article touches upon the issue of the potential to improve secondary school teacher professional expertise in Australia. These are initiatives approved by Australian specific organizations at government and non-government levels. The author describes the goals and directions of secondary school teacher government support and government strong requirements for teacher professional learning. The article also considers the role of Australian professional education organizations in teacher professional growth. The analysis of the goals is carried out by means of government and professional education organizations documents. The author reports that social context of secondary school teacher professional development in Australia is provided through government education institutions. In support of this fact there is a range of government projects, programmes and documents approved at international and national levels and aimed to encourage lifelong quality teacher development. Furthermore, teacher professional development support is also organized by various Australian professional associations that work collaboratively. Moreover, these associations are not only focused on teacher professional development national standards, requirements and forms but global trends in professional learning and performance.

Key words: teacher professional development, professional profile, initiatives, strategy, reforms, social demand, professional associations.

\section{INTRODUCTION}

Quality teacher professional development strategy design in schools as an effective learning environment is a source of concern for Australian educators. However, in spite of increased interest and thorough analysis, Australia generates educational reforms being slow and in some cases inefficient as well as bringing up issues to be solved. In contrast to general thought, student outcomes are not directly connected with strong aspirations, strong responsibility, complicated tests, much time for tasks, new curriculum and materials, computers or up-to-date laboratory equipment. Improved student learning outcomes are the result of improved teacher efficacy aimed at average students. Therefore, Australian educators are strongly encouraged to seek for effective strategies and initiatives to achieve quality teaching.
\end{abstract}




\section{THE AIM OF THE STUDY}

The aim of the study is to analyze government and non-government initiatives for secondary school teacher professional development in Australia and define their role in teacher professional growth.

\section{THEORETICAL FRAMEWORK AND RESEARCH METHODS}

Thorough analysis of theoretical materials and the use of appropriate information sources enabled us to adequately investigate the question. To obtain necessary information, there have been used such research methods as comparative analysis of the Australian research and pedagogical periodicals, the documents of the Ministry of Education of Australia and education organizations on teacher professional development; EURIDICE, OECD, UNESCO reports; interpretative-analytical method with application of analysis, synthesis, content-analysis, and theoretical summarization.

A lot of Australian renowned educators and researchers devoted their works to investigating quality teaching and improving learning environment. Among them are A. Bertany, C. Bourke, B. J. Caldwell, N. Dempster, S. Dinham, B. Jensen, J. Killion, M. Lloyd, J. Marshall, P. Santiago, H. Timperley, K.Tuinamuana, A.Willson and the others. Government and non-government organizations reports indicate that teacher support at deferent levels has come into sharp focus in recent years and hence they have a range of significant facts and concepts to improve teacher professional development.

\section{RESULTS}

Teacher professional growth is considered to be the key element in teacher quality improvement general strategy premised on dynamic development, competent recognition and educators' strong support at proper levels. It is suggested that continuous professional development takes place in school learning environment. The Constitution of Australia claims that school education (primary and secondary schools) is primarily responsibility of Australian states and territories. The Department of education, employment and workplace relations describes the division of such responsibilities in the following way: "while the Australian government plays a leadership role in driving forward educational reforms and provides funding for areas of national educational importance, school education in Australia is principally the constitutional responsibility of the states and territories ... for the delivery and management of schooling" (Commonwealth of Australia, 2013).

Typical secondary school teacher professional profile comprises the following characteristics: firstly, teachers teach one or several subjects of a curriculum and provide students' social, emotional, intellectual and physical development. Secondly, according to TALIS report, (OECD, 2013), 59\% of teachers in Australia are women and they are 43 years old on average. Thirdly, $100 \%$ of teachers completed university or other equivalent higher education institution, $98 \%$ completed teacher education or a training programme. Fourthly, a typical teacher in Australia has an average of 17 years of teaching experience. Fifthly, $84 \%$ of teachers have permanent employment. Sixthly, 9 in 10 teachers in Australia are satisfied with their job; only $39 \%$ of teachers think that teaching is socially valued.

It is important to mention that $97 \%$ of teachers in Australia have universal access to professional development opportunities (OECD, 2013). It means that most teachers working in Australian schools have strong access to induction programmes and at-work mentoring support.

Thus, above-mentioned facts prove a teacher to be a key element of Australian education system. In general, there is an increasing investment in teacher development at all levels of the education in Australia. Social context of teacher professional development is revealed through government and professional support. First of all, one should consider the 
Government secondary school teacher demand and support. The evidence of social demand at all levels of the education system in Australia is the endorsement of the Australian Teacher Performance and Development Framework and the Australian Charter for the Professional Learning of Teachers and School Leaders by all Education ministers in 2012 (AITSL, 2014). The Australian Teacher Performance and Development Framework outlines the essential requirements to create a performance and development culture in Australian schools (AITSL, 2012).

The Australian Teacher Performance and Development Framework is based on the National Professional Standards for Teachers and is created for teacher career growth guarantee including such official procedures as highly accomplished and lead specialist certification and teacher registration. The core of the Framework is Performance and Development Cycle within which there are three essential elements: reflection and goal setting, professional practice and learning and feedback and review. The key elements of Performance and Development Culture are clear understanding of effective teaching, leadership, flexibility, coherence, and focus on student outcomes.

The Government requirements to quality teaching are outlined in the Australian Charter for the Professional Learning of Teachers and School Leaders. Professional learning is considered as an effective way to develop individual and collective capacity across the teaching profession to correspond to current and future challenges. The Charter describes the characteristics of a high quality professional learning. They are:

- relevance,

- collaboration,

- future focused orientation (AITSL, 2012).

Hence, both graduate teachers and teachers with considerable teaching experience are actively supported at government level. In December, 2008 the National initiatives in educational system of Australia encouraged the Education ministers from the states, territories and the Commonwealth countries to release the Melbourne Declaration on Educational Goals for Young Australians. The Declaration proclaims equity and high quality of the educational system of Australia. Achieving the educational goals does not rest solely on one group of learning process but "the collective responsibility of governments, school sectors and individual schools as well as parents, young Australians, families, education and training providers, business and broader community" (Commonwealth of Australia, 2013).

In addition to the Declaration, the Ministers released a Four Year Plan which sets out the strategies and initiatives aimed to improve teacher learning at a national level, with state and territory support. The Government support for teacher professional development includes seven reforms. They are:

1. National Professional Standards for Teachers.

2. National system of accreditation of initial teacher education programs.

3. Nationally consistent approach to teacher registration.

4. National approach to the Certification of Highly Accomplished and Lead Teachers.

5. Professional development needs for principles and school leaders.

6. National Professional Standards for Principles.

7. Australian Curriculum (Commonwealth of Australia, 2013).

To promote the above-listed reforms, the Australian Government created the Australian Institute for Teaching and School Leadership (AITSL), i.e., the national organization of the Education Ministers of all states and territories. The aim of AITSL is 
"to provide national leadership for Commonwealth, state and territory governments in promoting excellence in the profession of teaching and school leadership" (Tuinamuana, 2011). It is AITSL that has been responsible for creating and promoting the National Professional Standards for Teachers since 2011.

The analysis of this document shows that the standards are the core of the teacher quality reforming programme. In response to the National Partnership Agreement on Improving Teacher Quality, all states and territories came to the agreement to develop and implement the complex of nationally concerted standards in 2011.

Special attention should be paid to the fact that government and national organizations have a strong concern in secondary school teacher professional development and consequently create relevant documents for support of Australian education system ambitions and goals. The National Professional Standards for Teachers represent a public statement of what constitutes teacher quality. The Standards define the teacher's work and make explicit the elements of teacher professional development social context in $21^{\text {st }}$ century (AITSL, 2011). The Standards comprise seven standards which outline teacher capacity. A detailed study of this document showed that the standards are coherent, interdependent and partly coincident. The Standards are organized according to the following domains of teaching:

- professional knowledge;

- professional practice;

- professional engagement.

In seeking to define purposes and principles for a teacher assessment process, AITSL developed the Certification of Highly Accomplished and Lead Teachers in Australia. The Certification is an important element in a teacher quality strategy and ensures the certification processes of teachers. The Certification being a means of assessment is standards-based and is focused on student outcomes. Besides, it is a part of a broader approach to career stages which includes professional learning and professional practice and development assessment. The document is credible when the assessment processes of teacher performance are grounded on rigorous, valid, reliable and transparent measures. Moreover, the Certification being an effective professional growth stimulus is premised on the best national and international practice and encourages the development of evidence about what works in recognizing teacher quality (AITSL, the Certification, 2012).

Another demonstration of the government support for teacher professional development is the Australian Government Quality Teacher Programme (AGQTP) designed by federal governments. The Programme outlines the essence of Australian educational reforms and contributes to the purposes of the National Partnership Agreement on Improving Teacher Quality. The purposes of the programme are triune: century;

1) to equip teachers with skills and knowledge needed for teaching in the $21^{\text {st }}$

2) to provide national leadership in high priority areas of professional learning;

3) to improve the professional standing of school teachers and leaders.

The Programme ensures as follows:

1) effective training of principals, teachers and school leaders for their roles and school environment;

2) developing teachers for enhancing skills and knowledge throughout their careers;

3) equipping teachers with skills to encourage young people to meet basic literacy and numeracy standards;

4) support for the implementation of the National Teacher Professional Standards; 
5) support for the implementation of the Australian Curriculum;

6) abilities of teachers and schools leaders to effectively implement student well being in schools, including managing bullying (Department of Education, Employment and Workplace Relations, 2012).

It is important to highlight the role of federal governments in teacher professional development support. Some years ago the state and territory governments of Australia in relation to quality teaching implemented such initiatives as:

1. The competency framework for teachers in Western Australia

2. The establishment of generic professional standards for teachers in Queensland.

3. The establishment of the Ministerial Advisory Committee for the Victorian Institute of teaching.

4. Recommendations in the New South Wales "Quality Matters" report.

5. Professional development programs in the Northern Territory.

6. Teacher registration principles in Australian Capital Territory, South Australia and Tasmania (The Federal Department of Education, 2001).

Such initiatives demonstrate the strong aspiration of the Australian Government to recognize and promote future-focused innovations in the educational system, professional learning and teaching.

In addition, the Australian Government is passionate about professional development approaches that had already been generally recognized and demonstrated strong impact on teaching practice and student outcomes in some other successful organizations. It is about the Global trends in professional learning and performance and development completed by AITSL in 2013 (AITSL, 2014). The document set out to study fifty organizations in ten countries including Austria, Great Britain, India, Japan, Finland, and the USA to discover innovative approaches in professional learning and development. Examining those approaches revealed five trends in teacher professional learning and development and performance:

1. Integrated trend suggests that professional learning and development and performance are connected and constitute organizational culture and practice.

2. Immersive trend incentivises holistic experiences that challenge aspirations and values and alters teaching practice.

3. Design-led trend promotes powerful forms of professional learning and development and performance and problem-solving processes.

4. Market-led trend ensures stimulating demand by new providers and growing the market for new goods and services.

5. Open trend stimulates free ideas and resources exchange in unregulated online environments (AITSL, 2014).

It should be stressed that a number of different Australian professional associations are actioned for the effect of teacher performance and students outcomes. These are the Australian Science Teachers' Association, the Australian Association of Teachers of English, the Australian Literacy Educators of Australia, the Australian Association of Mathematics Teachers, the Australian Education Union, the Australian Institute of Teaching and Development. These professional associations are funded at a national level in order to develop subject specific standards for a highly accomplished teacher.

Two large professional associations that undertake continuous research in the area of teacher professional development should be considered in more detail. They are the Curriculum Corporation and the Australian Council for Educational Research (ACER). 
The Curriculum Corporation is a leading national organization which provides curriculum and programmes development and high quality education materials to schools and systems. It offers on-line services in teacher professional development. The Corporation also publishes "EQ Australia", a teacher journal that provides research works of Australian educators and researchers in curriculum and teacher professional performance. The Curriculum Corporation arranges annual national forums for teachers and school leaders to discuss current issues in pedagogy, professional learning and teaching (The Federal Department of Education, 2001).

The analysis of an annual ACER 2013 report shows that the Australian Council for Educational Research is an independent research organization whose goals are research in pedagogy, assessment, date collection and processing to provide professional support for educators, teachers and school leaders. ACER offers participation in conferences, seminars and practicals. It develops up-to-date professional development programmes and specialized projects for educators. It also cooperates with education institutions at national and international levels (ACER, 2014).

\section{CONCLUSIONS}

Research works and documents of Australian government and non-government education institutions enable us to state that secondary school teacher professional development is now recognised as vitally demanded element in policies at all levels. Most Australian schools receive supplementary funding from the Government and therefore have to operate under the National educational Goals in Australia. A number of documents and reports claim that teachers are key elements of student development and outcomes having a universal access to various professional development opportunities.

Social context of secondary school teacher professional development in Australia is provided through government education institutions. In support of this fact there is a range of government projects, programmes and documents approved at international and national levels and aimed to encourage lifelong quality teacher development. Furthermore, teacher professional development support is also organised by various Australian professional associations that work collaboratively. Moreover, these associations are not only focused on teacher professional development national standards, requirements and forms but global trends in professional learning and performance.

There are contradictions between the Australian education institutions' demand for skilled specialists and the system of professional training that have certain connotations with secondary school teacher professional development issue. Therefore, our further studies will be premised on the study of organizational and pedagogic conditions of secondary school teacher professional development in Australia.

\section{REFERENCES}

1. ACER. (2014). Annual report 2012-2013. Melbourne, p. 38.

2. AITSL. (2012). Australian Charter for the Professional Learning of Teachers and School Leaders. Melbourne, Brisbane, Canberra, p. 10.

3. AITSL. (2012). Australian Teacher Performance and Development Framework. Melbourne, Brisbane, Canberra, p. 14.

4. AITSL. (2012). Certification of Highly Accomplished and Lead Teachers in Australia. Melbourne, Brisbane, Canberra, p. 26. 
5. AITSL. (2014). Global trends in professional learning and performance \& development. Some implications and ideas for the Australian education system. Melbourne, Canberra, p. 36.

6. AITSL. (2011). National Professional Standards for Teachers. Melbourne, p. 24.

7. Commonwealth of Australia. (2013). The Senate. Education, Employment and Workplace Relations References Committee. Teaching and learning - Maximising our investment in Australian schools. The Senate Printing Unit, Parliament House, Canberra, p. 116.

8. Department of Education, Employment and Workplace Relations. (2012). Funding recipient. Guidelines 2011-2013. Canberra, p. 12.

9. Freeman, C., O’Malley, K., Eveleigh, F. (2014). Australian teachers and the learning environment: An analysis of teacher response to TALIS 2013: Final Report. Melbourne: ACER, p. 204.

10. OECD. (2013). Australia. Country note. Results from TALIS, p. 4.

11. OECD. (2009). Professional development of teachers in Creating Effective Teaching and Learning Environments: First Results from TALIS. p. 48-86.

12. The Federal Department of Education, Training and Youth Affairs and the South Australian Department of Education, Training and Employment. (2001). National report on the development of education in Australia. Geneva, p. 73.

13. Tuinamuana, K. (2011). Teacher Professional Standards, Accountability, and Ideology: Alternative Discourses. Australian Journal of Teacher Education, Vol. 36, No 12 , p. $72-82$. 